\title{
Methylmalonyl-CoA mutase from Propionibacterium shermanii
}

\author{
Evidence for the presence of two masked cysteine residues
}

\author{
E. Neil MARSH and Peter F. LEADLAY* \\ Department of Biochemistry, University of Cambridge, Tennis Court Road, Cambridge CB2 1QW, U.K.
}

\begin{abstract}
Adenosylcobalamin-dependent methylmalonyl-CoA mutase from Propionibacterium shermanii contains no intramolecular disulphide bridges, but two of the six thiol groups in the heterodimer are only revealed after reduction of the denatured enzyme with dithiothreitol. The available evidence suggests that they are present in disulphide linkages to unknown thiols of low $M_{\mathrm{r}}$. The two specifically masked cysteine residues are Cys-535 in the $\alpha$-subunit and Cys-517 in the $\beta$-subunit, which occupy exactly homologous positions in each chain.
\end{abstract}

\section{INTRODUCTION}

$5^{\prime}$-Deoxyadenosylcobalamin is an essential cofactor for a number of enzymes that catalyse unusual rearrangements of carbon skeletons (Halpern, 1985; Golding \& Rao, 1986), including the interconversion of $(2 R)$ methylmalonyl-CoA and succinyl-CoA (3-carboxypropionyl-CoA) catalysed by methylmalonyl-CoA mutase (EC 5.4.99.2) (Kellermeyer \& Wood, 1969). The possible role of the cobalamin in all these reactions has been extensively studied, and there is general agreement that the homolytic cleavage of the cobalt-carbon bond is the first step in the rearrangement (Halpern, 1985; Golding \& Rao, 1986). The stereochemical course of the methylmalonyl-CoA mutase-catalysed reaction has been mapped in some detail (Hull et al., 1988), but further progress in understanding the mechanism has been hampered by a lack of information about the structure of the enzyme.

Methylmalonyl-CoA mutase is most conveniently purified from the Gram-positive bacterium Propionibacterium shermanii (syn. freudenreichii) (Francalanci et al., 1986). Recently the structural genes for the two dissimilar subunits have been cloned and sequenced in this laboratory (Marsh et al., 1989a), so that the entire primary structure of the enzyme is now known. In addition, the mutase from $P$. shermanii is the only adenosylcobalamin-dependent enzyme that has been obtained in a crystalline form suitable for high-resolution X-ray crystallography (Marsh et al., 1988).

Anomalous kinetic isotope effects observed with several adenosylcobalamin-dependent enzymes led Cleland (1982) to propose that a protein side chain might act as an additional carrier of hydrogen during the rearrangement. Numerous reports that many of these enzymes are sensitive to thiol-directed reagents have prompted others (O'Brien et al., 1985; Stubbe, 1988) to speculate that this protein-based carrier might be a thiyl radical. We have therefore used chemical modification to investigate the reactivity of cysteine side chains in methylmalonyl-CoA mutase from $P$. shermanii.

\section{EXPERIMENTAL}

\section{Materials}

Iodoacetic acid and dithiothreitol were from Sigma
Chemical Co., Poole, Dorset, U.K. Guanidinium chloride (AristaR grade) was obtained from BDH Chemicals, Poole, Dorset, U.K. Iodo[2- ${ }^{14}$ C]acetic acid $(2.1 \mathrm{GBq} /$ $\mathrm{mmol}$ ) was from Amersham International, Amersham, Bucks., U.K. Sephadex G-50 (medium grade) was supplied by Pharmacia, Uppsala, Sweden. The sources of all other reagents and chemicals have been given previously (Francalanci et al., 1986).

\section{Protein assay}

Protein was determined by the method of Bradford (1976), with bovine serum albumin as standard.

\section{Enzyme assays}

Methylmalonyl-CoA mutase was assayed at $37^{\circ} \mathrm{C}$, with succinyl-CoA as substrate, essentially by the method of Zagalak et al. (1974).

\section{Polyacrylamide-gel electrophoresis}

Polyacrylamide-gel electrophoresis of methylmalonylCoA mutase, and of peptides derived from it, was performed in the system of Laemmli (1970). When proteins contained radioactivity, gels were soaked in Amplify (Amersham International) after electrophoresis, dried on to Whatman 3MM filter paper, and subjected to fluorography at $-80^{\circ} \mathrm{C}$ with the use of pre-flashed X-ray film (Fuji RX Medical).

\section{Analytical sedimentation in guanidinium chloride}

Procedures for making sedimentation-equilibrium measurements on the mutase $(3 \mathrm{mg} / \mathrm{ml})$ in $2 \mathrm{M}$-guanidinium hydrochloride were, with minor changes of detail, as described by Marsh et al. (1989b). Values for the 'whole-cell' weight-average $M_{\mathrm{r}}\left(M_{\mathrm{r}, \mathrm{w}}^{0}\right)$ of the mutase were computed by using the averaging procedure of Creeth \& Harding (1982).

\section{Reaction of methylmalonyl-CoA mutase with iodo[2- ${ }^{14}$ Clacetic acid \\ Methylmalonyl-CoA mutase $(1-10 \mathrm{mg} / \mathrm{ml})$ was incu- bated briefly, at $30^{\circ} \mathrm{C}$, in $50 \mathrm{~mm}-\mathrm{Tris} / \mathrm{HCl}$ buffer, pH 7.5, containing $5 \mathrm{~mm}$-EDTA and $5 \mathrm{M}$-guanidinium chloride. Iodo $\left[2-{ }^{14} \mathrm{C}\right]$ acetic acid $(50 \mathrm{~Bq} / \mathrm{nmol})$ was added, to a final concentration of $3 \mathrm{~mm}$. The mixture was}

\footnotetext{
* To whom correspondence should be addressed.
} 
incubated at $30{ }^{\circ} \mathrm{C}$ under $\mathrm{N}_{2}$ for $30 \mathrm{~min}$, and then dialysed against several changes of $0.5 \%(\mathrm{w} / \mathrm{v}) \mathrm{NH}_{4} \mathrm{HCO}_{3}$ solution. The non-diffusible material was assayed for protein, and samples were counted for radioactivity.

In some experiments, $10 \mathrm{~mm}$-dithiothreitol was included in the incubation. After $30 \mathrm{~min}$, and before iodoacetate was added, this was removed by centrifuging the solution through a small column by Sephadex G-50 equilibrated with the same buffer (Helmerhorst \& Stokes, 1980). Native apo-mutase, when treated with iodoacetic acid, retained full enzymic activity. In the absence of denaturant, no radioactivity was incorporated after incubation with iodo $\left[{ }^{14} \mathrm{C}\right]$ acetate, into either apoenzyme or the pink cofactor-containing form of the mutase (Francalanci et al., 1986).

In other experiments, denatured methylmalonyl-CoA mutase was treated with hydroxylamine (final concentration $0.4 \mathrm{M}, \mathrm{pH} 7.5$ ) for $1 \mathrm{~h}$ at $37^{\circ} \mathrm{C}$. The hydroxylamine was removed by rapid filtration through Sephadex G-50 and the protein was labelled with iodo $\left[{ }^{14} \mathrm{C}\right]$ acetic acid as described above.

\section{Preparation and analysis of $\mathbf{C N B r}$-cleavage peptides}

Methylmalonyl-CoA mutase $(1-10 \mathrm{mg} / \mathrm{ml})$, dissolved in $70 \%(\mathrm{v} / \mathrm{v})$ formic acid, was treated with a 30 -fold excess (w/w) of $\mathrm{CNBr}$ at $20^{\circ} \mathrm{C}$ overnight in the dark under $\mathrm{N}_{2}$. The mixture was diluted 10 -fold with distilled water and freeze-dried over $\mathrm{NaOH}$ pellets. Peptides were separated by polyacrylamide-gel electrophoresis in the presence of SDS and detected by staining with Coomassie Brilliant Blue (BDH Chemicals). Alternatively, they were separated by using a Pharmacia f.p.l.c. apparatus fitted with a $\mathrm{C}_{8}$ ProRPC-HR 5/10 reverse-phase column. Peptides were eluted with $0.3 \%(\mathrm{v} / \mathrm{v})$ trifluoroacetic acid solution in an increasing gradient of acetonitrile. Samples of each fraction were counted for radioactivity, and analysed by SDS/polyacrylamide-gel electrophoresis as described above.

\section{Preparation and analysis of chymotryptic-digest peptides}

Methylmalonyl-CoA mutase $(2 \mathrm{mg})$ in $0.1 \mathrm{ml}$ of $0.5 \%$ $\mathrm{NH}_{4} \mathrm{HCO}_{3}$ was digested with $40 \mu \mathrm{g}$ of tosyl-lysyl-chloromethane- ('TLCK'-)treated chymotrypsin (Worthington Corp., Freehold, NJ, U.S.A.) at $37^{\circ} \mathrm{C}$. After 1 h, another $40 \mu \mathrm{g}$ of chymotrypsin was added, and digestion was allowed to continue for a further $3.5 \mathrm{~h}$. The mixture was diluted to $1 \mathrm{ml}$ and freeze-dried.

Initial separation of peptides was performed by gel filtration on a TSK 2000 SWG column $(21.5 \mathrm{~mm} \times 300 \mathrm{~mm})$ (Anachem, Luton, Beds., U.K.) and h.p.l.c. (Varian 5000 liquid chromatograph) (Fig. 2a). Fractions containing radioactivity were pooled and freeze-dried. Further separation of radioactive peptides was achieved by using a $\mathrm{C}_{18}$ reverse-phase column (Varian MCH 5-ncap, $4 \mathrm{~mm} \times 150 \mathrm{~mm}$ ). Peptides were eluted with a gradient of $0-60 \%(\mathrm{v} / \mathrm{v})$ acetonitrile in $0.1 \%$ trifluoroacetic acid. Two radioactive peptides were detected (Fig. $2 b$ ). A sample of one of these, which was eluted at higher acetonitrile concentration, was submitted to automated $\mathrm{N}$-terminal sequence analysis on an Applied Biosystems $470 \mathrm{~A}$ sequencer, fitted with an on-line amino acid phenylthiohydantoin analyser (Applied Biosystems, Foster City, CA, U.S.A.). The second peptide was insufficiently pure, and obtained in insufficient yield, for reliable sequence analysis.

\section{RESULTS AND DISCUSSION}

Methylmalonyl-CoA mutase as isolated from $P$. shermanii (Francalanci et al., 1986) contains two major forms separable by f.p.l.c.: a colourless apoenzyme that requires added adenosylcobalamin for enzymic activity, and an inactive pink form that contains tightly bound cobalamin. Even when pretreated with a reducing agent such as dithiothreitol, neither of these protein species was found to contain radioactivity after treatment with iodo $\left[{ }^{14} \mathrm{C}\right]$ acetate or iodo $\left[{ }^{14} \mathrm{C}\right]$ acetamide, and the specific enzymic activity of the apoenzyme was unaffected. However, when the treatment with iodo $\left[{ }^{14} \mathrm{C}\right]$ acetic acid was carried out after denaturation of the enzyme in $5 \mathrm{M}$ guanidinium chloride, both apoenzyme and the pink mutase form became labelled. In both cases approx. $4 \mathrm{~mol}$ of ${ }^{14} \mathrm{C}$ label was incorporated per mol of mutase (Table 1). Pretreatment with dithiothreitol as described in the Experimental section resulted in an additional approx. 2 mol of ${ }^{14} \mathrm{C}$ label being incorporated per mol of mutase for both forms. Identical results were obtained for enzyme purified from different batches of cells. Cobalamin appeared to remain bound to the corrincontaining form of the enzyme even in $5 \mathrm{M}$-guanidinium chloride. However, treatment with dithiothreitol rapidly converted the pink colour into yellow in $5 \mathrm{M}$-guanidinium chloride, and this unidentified yellow compound was readily removed from the protein by dialysis or gel filtration.

These results indicate the presence of four reactive thiol groups, probably cysteine residues, in the $\alpha \beta$ dimer with a further two cysteine residues in some way protected from reaction with iodoacetate unless the protein has been pretreated with dithiothreitol under denaturing conditions. This agrees well with the amino acid sequence for the mutase deduced from the sequence of the cloned structural genes: this shows that the small $(\beta)$ subunit contains four and the larger $(\alpha)$ subunit contains two cysteine residues.

Experiments were carried out in order to localize the two unreactive cysteine residues within the amino acid sequence of the enzyme. Methylmalonyl-CoA mutase

Table 1. Labelling of methylmalonyl-CoA mutase by iodoacetate under denaturing conditions

Both the apoenzyme and the cobalamin-binding 'pink' form of the enzyme show similar labelling patterns. Approx. $4 \mathrm{~mol}$ of iodoacetate $/ \mathrm{mol}$ of enzyme is incorporated. If the enzyme is pretreated with dithiothreitol, a further $2 \mathrm{~mol}$ of label is incorporated. No increase in the incorporation of label is seen if the enzyme is pretreated with hydroxylamine. For experimental details see the text.

\begin{tabular}{lcc}
\hline & \multicolumn{2}{c}{$\begin{array}{c}\text { Iodoacetate incorporated } \\
(\mathrm{mol} / \mathrm{mol} \text { of mutase })\end{array}$} \\
\cline { 2 - 3 } Treatment & Apoenzyme & $\begin{array}{c}\text { Cobalamin-containing } \\
\text { enzyme }\end{array}$ \\
\hline $\begin{array}{l}\text { Iodoacetate } \\
\begin{array}{l}\text { Dithiothreitol then } \\
\text { iodoacetate }\end{array}\end{array}$ & $4.3 \pm 0.3$ & $3.7 \pm 0.2$ \\
$\begin{array}{c}\text { Hydroxylamine then } \\
\text { iodoacetate }\end{array}$ & $3.6 \pm 0.3$ & $6.2 \pm 0.3$ \\
\hline
\end{tabular}




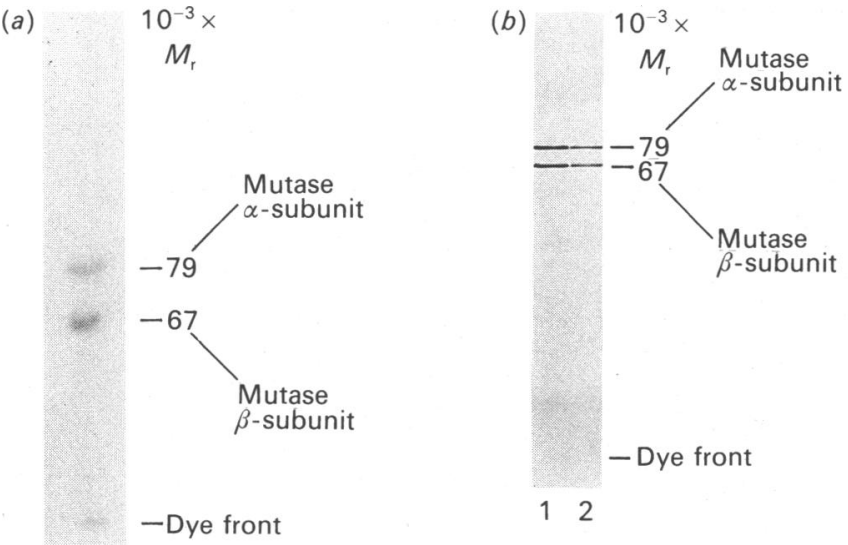

Fig. 1. Electrophoresis of methylmalonyl-CoA mutase on SDS/ polyacrylamide gels

(a) Fluorograph of the specifically labelled mutase, after electrophoresis on a $10 \%$ polyacrylamide gel. The 'masked' cysteine residues were specifically labelled with iodo[ $\left[2{ }^{14} \mathrm{C}\right]$ acetate as described in the text. (b) Separation of subunits of the mutase by electrophoresis on a $15 \%$ gel: lane 1 , in the absence of dithiothreitol; lane 2 , in the presence of dithiothreitol. Protein was stained with Coomassie Blue as described in the text.

was first incubated with unlabelled iodoacetate in the presence of guanidinium chloride, as described above. Removal of the excess reagent was followed by treatment with dithiothreitol, which was in turn removed by rapid gel filtration. Newly liberated thiol groups were then labelled by incubation with iodo $\left[{ }^{14} \mathrm{C}\right]$ acetic acid. Radioactivity was incorporated corresponding to 1.0 1.5 cysteine residues labelled per dimer. The variation in these results may be due to some inefficiency in the rapid removal of iodoacetate before dithiothreitol treatment. It is consistent with this explanation that, when iodo$\left[{ }^{14} \mathrm{C}\right]$ acetate was used first, and unlabelled iodoacetate was used after treatment with reducing agent, radioactivity was incorporated corresponding to about 4.5 cysteine residues labelled per dimer. Samples of the mutase modified with dithiothreitol were subjected to SDS/polyacrylamide-gel electrophoresis (Fig. 1a). Fluorography of this gel showed that both subunits were labelled, suggesting that the masked cysteine residues were present on different subunits.

SDS/polyacrylamide-gel electrophoresis in the presence and in the absence of dithiothreitol (Fig. 1b) shows that no inter-subunit disulphide bond is present in the denatured enzyme. This was confirmed by sedimentationequilibrium measurements in $2 \mathrm{M}$-guanidinium chloride: the 'whole-cell' weight-average $M_{\mathrm{r}}\left(M_{\mathrm{r}, \mathrm{w}}^{0}\right)$ was found to be $68000 \pm 5000$ in the absence of dithiothreitol and $70000 \pm 5000$ in its presence. These values should be compared with a value of $116000 \pm 5000$ for the native mutase under the same conditions of $\mathrm{pH}$, temperature, buffer and protein concentration (Marsh et al., 1989b). Therefore these two thiol groups are not linked to each other through a conventional disulphide bridge.

The amino acid sequence around one of these masked cysteine residues was determined before the nucleotide sequence of the genes was known: samples of the mutase, radiolabelled with iodo $\left[{ }^{14} \mathrm{C}\right]$ acetate after dithiothreitol
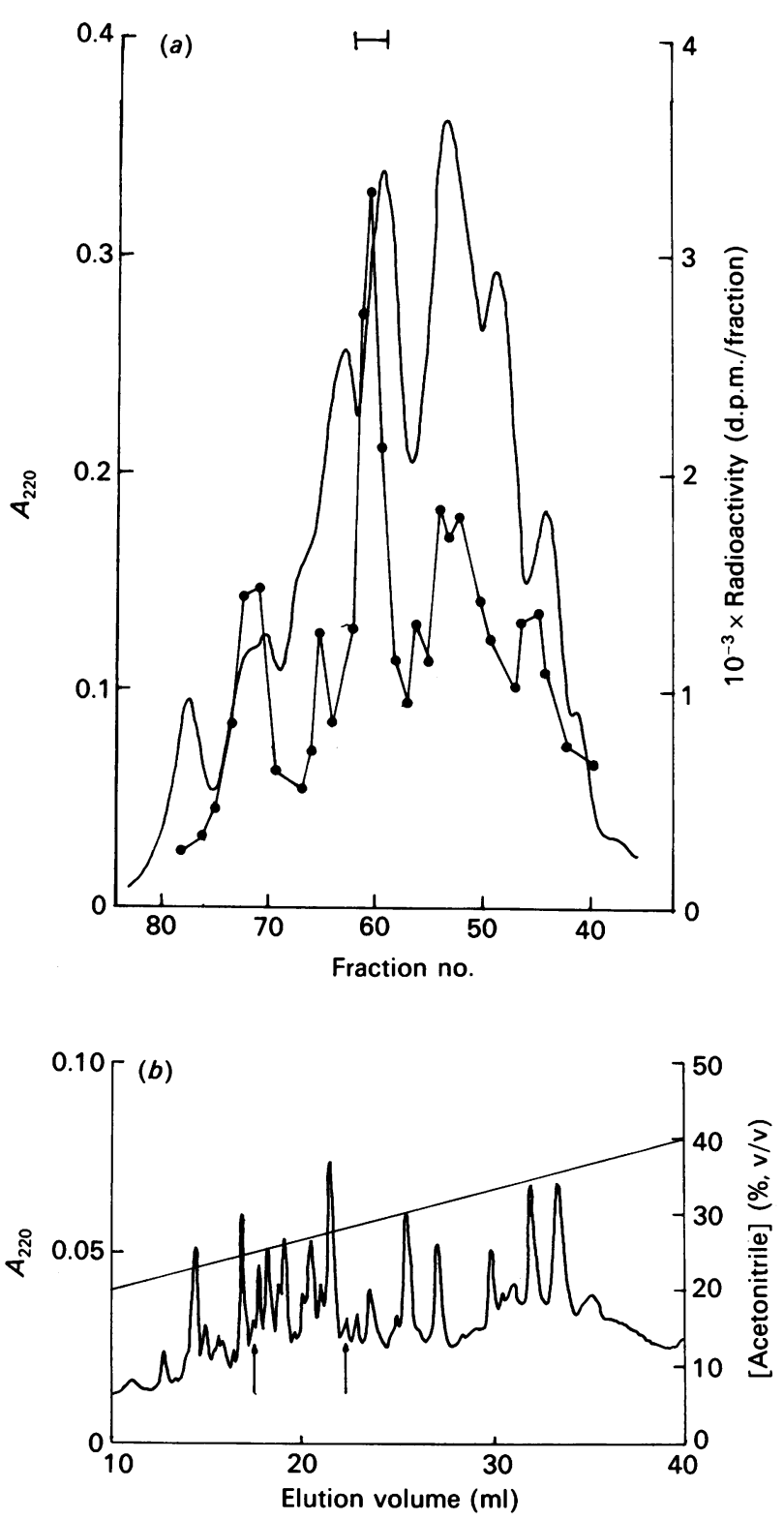

Fig. 2. Purification of radiolabelled peptides from a chymotryptic digest of methylmalonyl-CoA mutase

(a) Gel filtration on a TSK 2000 SWG h.p.l.c. column. For details see the text. $\longrightarrow, A_{220} ; \bigcirc$, radioactivity. Fractions 58-61 containing the major radioactive peak were pooled as indicated by the bar. (b) Chromatography on a $\mathrm{C}_{18}$ reverse-phase h.p.l.c. column. For details see the text. The pooled fractions from the previous step were chromatographed with a gradient of acetonitrile in $0.1 \%$ trifluoroacetic acid. Each peak was collected manually. Two that were found to be radioactive are indicated by arrows. The second of these peptides was sufficiently pure after this step for it to be sequenced. The other radioactive peptide was insufficiently pure and recovered in insufficient yield for reliable sequence analysis.

treatment, were digested with chymotrypsin, and peptides were purified as described in the Experimental section. Fractions 58-61, which contained the bulk of the radioactivity applied, were pooled and purified further on a reverse-phase column (Fig. $2 b$ ). A radioactive fraction from this second column contained a peptide sufficiently 


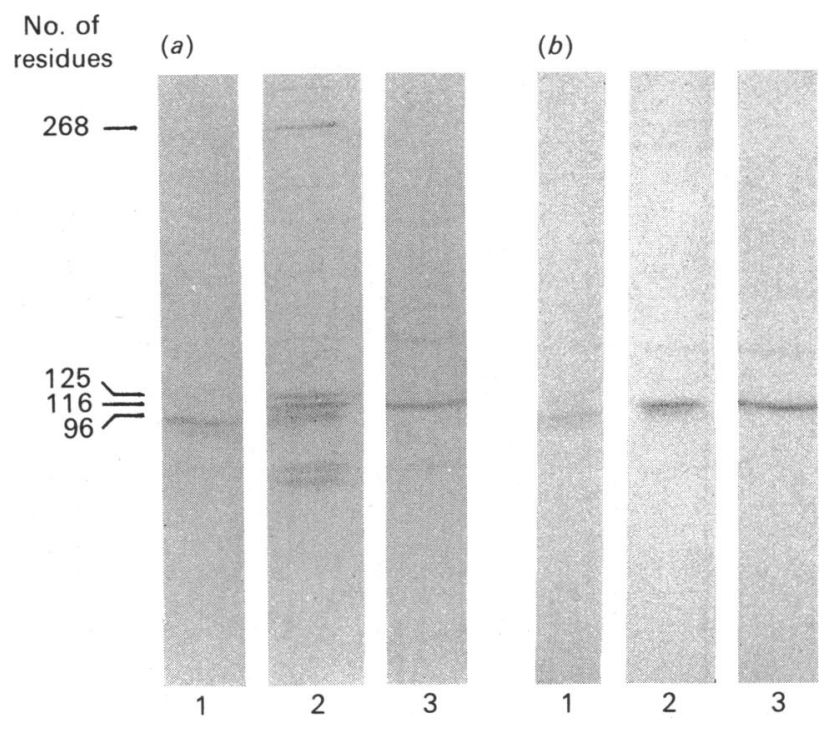

Fig. 3. Mapping of peptides generated from $\mathrm{CNBr}$ cleavage of methylmalonyl-CoA mutase

$\mathrm{CNBr}$-derived fragments were subjected to electrophoresis on an SDS $/ 27 \%$ polyacrylanide gel as described in the text. Panel $(a)$ : lanes from a Coomassie Blue-stained gel. Panel $(b)$ : fluorography of the corresponding lanes in panel $(a)$. Lane 1, 96-residue cysteine-containing peptide derived from the mutase $\alpha$-subunit; lane 2, total $\mathrm{CNBr}$ digest of the mutase; lane 3,116 -residue peptide derived from mutase $\beta$-subunit. The latter peptide contains two cysteine residues, one of which had been previously shown to be labelled by iodoacetate.

pure for automated $N$-terminal sequence analysis. A second radioactive fraction was detected but did not yield a pure peptide even after further chromatography. These two fractions accounted for $50 \%$ of the radioactivity applied to the column and $90 \%$ of the total radioactivity recovered. The sequence of the first four residues of the purified peptide was determined to be L-A-CmC-L (where $\mathrm{Cm}$ represents carboxymethyl), with essentially all of the radioactivity being released after the third round of degradation. Once the complete amino acid sequence had been determined (Marsh et al., 1989a) this was seen to correspond to residues $515-518$ in the sequence of the $\beta$-subunit of mutase, so that the labelled residue must be Cys-517. Knowledge of the complete sequence then allowed the identity of the second masked cysteine group to be established by peptide mapping of large fragments, generated by cleavage of the specifically carboxy $\left[{ }^{14} \mathrm{C}\right]$ methylated mutase with $\mathrm{CNBr}$.

Fractionation of the labelled $\mathrm{CNBr}$-digested mutase was achieved by using reverse-phase f.p.l.c.: radioactivity was eluted in two major peaks, representing about $60 \%$ of the radioactivity applied to the column. Analysis of these fractions by SDS/polyacrylamide-gel electrophoresis showed that the major peptide from the second peak corresponded in size to a predicted 96-residue peptide from the $\alpha$-subunit, containing a single cysteine residue, Cys-535. The major peptide component of the first radioactive peak corresponded in size to a 116residue peptide from the $\beta$-subunit, predicted to contain both Cys-517 and Cys-568. The latter group had already been shown to be one of the specifically radiolabelled
531

541

Mutase $\alpha$-subunit

L L K L C I D A G R A M A

$++*++*+$

Mutase $\beta$-subunit

V F L A C I G T R R D F G

513

521

Fig. 4. Amino acid sequence around the two 'masked' cysteine residues of methylmalonyl-CoA mutase

Identical residues are marked by *, conservatively substituted residues by + .

thiol groups after dithiothreitol reduction of denatured mutase. Fluorography of the gel confirmed that, in their respective fractions, only these two peptides were significantly radiolabelled (Fig. 3). The yield of the peptide from the $\alpha$-subunit is noticeably lower, as judged by Coomassie Blue staining, and this is reflected in the lower amount of radioactivity detected in this band by fluorography. There is a small amount of radioactivity present in a band of higher $M_{\mathrm{r}}$ which is presumably the product of partial cleavage with $\mathrm{CNBr}$.

From these experiments taken together, it can be concluded that two specific cysteine residues, one in each subunit of methylmalonyl-CoA mutase, are shielded from reaction with iodoacetate even in $5 \mathrm{M}$-guanidinium chloride. Treatment of the denatured protein with dithiothreitol is apparently required in order to expose these residues to subsequent attack by iodoacetate. The masked residues occupy exactly equivalent positions in the sequence of the mutually homologous $\alpha$ - and $\beta$-subunits (Fig. 4), presumably a reflection of their very similar environments in the native protein.

As already noted, the effect of dithiothreitol is not due to the reduction of a conventional disulphide bond linking these two residues. Neither are they involved in thioester linkages, since hydroxylamine treatment is not effective in unmasking the two thiol groups (Table 1). Further, the unmasking of two additional thiol groups cannot be ascribed to the removal of the cofactor from its binding site, in view of the identical results obtained with the apoenzyme, where no cofactor is present. The most likely explanation is therefore that these two residues are involved in disulphide linkages with thiols of low $M_{\mathrm{r}}$, such as CoA. There have been several previous reports of such linkages in proteins, the clearest example being the essential active-site thiol group in streptococcal proteinase (Ferdinand et al., 1965), which is the only cysteine residue in that enzyme. The active-site cysteine residue was only exposed after reduction with either $\mathrm{NaBH}_{4}$ or dithiothreitol. Although the exact nature of this low- $M_{\mathrm{r}}$ material was not established, evidence was obtained that a volatile thiol was released by this treatment, which could subsequently be trapped by using $\mathrm{HgCl}_{2}$.

For the mutase, further work will be required to establish the chemical nature of both the putative thiol released by reduction and the yellow corrinoid released from the cofactor-containing form of the mutase.

The support of the Science and Engineering Research Council and the Medical Research Council is gratefully acknowledged. We thank Dr. S. E. Harding (University of 
Nottingham) for performing the analytical ultracentrifugation, and Dr. L. C. Packman of the Department of Biochemistry Protein Sequencing Facility (funded jointly by the Science and Engineering Research Council and the Wellcome Trust) for the automated determination of peptide sequences.

\section{REFERENCES}

Bradford, M. M. (1976) Anal. Biochem. 72, 248-254

Cleland, W. W. (1982) CRC Crit. Rev. Biochem. 13, 385-416

Creeth, J. M. \& Harding, S. E. (1982) J. Biochem. Biophys. Methods 7, 25-34

Ferdinand, W., Stein, W. H. \& Moore, S. (1965) J. Biol. Chem. 240, 1150-1155

Francalanci, F., Davis, N. K., Fuller, J. Q., Murfitt, D. \& Leadlay, P. F. (1986) Biochem. J. 236, 489-494

Golding, B. T. \& Rao, D. N. R. (1986) in Enzyme Mechanisms (Page, M. I. \& Williams, A., eds.), pp. 404-428, Royal Society of Chemistry, London

Received 28 July 1988/7 September 1988; accepted 28 December 1988
Halpern, J. (1985) Science 227, 869-876

Helmerhorst, E. \& Stokes, G. B. (1980) Anal. Biochem. 104, 130-135

Hull, W. E., Michenfelder, M. \& Rétey, J. (1988) Eur. J. Biochem. 173, 191-201

Kellermeyer, R. W. \& Wood, H. G. (1969) Methods Enzymol. 13, 207-215

Laemmli, U. K. (1970) Nature (London) 227, 680-685

Marsh, E. N., Leadlay, P. F. \& Evans, P. R. (1988) J. Mol. Biol. 200, 421-422

Marsh, E. N., McKie, N., Davis, N. K. \& Leadlay, P. F. (1989a) Biochem. J. 260, 345-352

Marsh, E. N., Harding, S. E. \& Leadlay, P. F. (1989b) Biochem. J. 260, 353-358

O'Brien, R. J., Fox, J. A., Kopczynski, M. G. \& Babior, B. M. (1985) J. Biol. Chem. 260, 16131-16136

Stubbe, J. (1988) Biochemistry 27, 3894-3900

Zagalak, B., Rétey, J. \& Sund, H. (1974) Eur. J. Biochem. 44, 529-535 